\title{
Aa. Vv., Ecritures en acte et genèse du texte
}

\section{Rachele Raus}

\section{(2) OpenEdition}

\section{Journals}

Édition électronique

URL : https://journals.openedition.org/studifrancesi/41422

DOI : $10.4000 /$ studifrancesi. 41422

ISSN : 2427-5856

Éditeur

Rosenberg \& Sellier

Édition imprimée

Date de publication : 1 juillet 2004

Pagination : 238-239

ISSN : 0039-2944

\section{Référence électronique}

Rachele Raus, «Aa. VV., Ecritures en acte et genèse du texte », Studi Francesi [En ligne], 142 (XLVIII | I) |

2004, mis en ligne le 30 novembre 2015, consulté le 09 septembre 2021. URL : http://

journals.openedition.org/studifrancesi/41422 ; DOI : https://doi.org/10.4000/studifrancesi.41422

Ce document a été généré automatiquement le 9 septembre 2021.

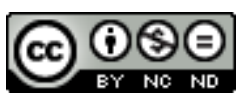

Studi Francesi è distribuita con Licenza Creative Commons Attribuzione - Non commerciale - Non opere derivate 4.0 Internazionale. 


\title{
Aa. Vv., Ecritures en acte et genèse du texte
}

\author{
Rachele Raus
}

\section{RÉFÉRENCE}

Ecritures en acte et genèse du texte, «Langage \& Société», n. 103, mars 2003, pp. 166.

1 Ce numéro de la revue a été conçu à la suite d'une journée d'étude ConsciLA (Confrontation en Sciences du langage) centrée sur l'approche génétique du texte (cf. l'œuvre d'Almuth Grésillon) et sur l'écriture en acte.

2 Claire DOCQUET-LACOSTE (Ecriture et traitement de texte à l'école élémentaire: modes d'analyse et pistes de travail, pp. 11-29) analyse les textes des enfants de l'école élémentaire utilisant le logiciel «Genèse du texte». Elle retrace les quatre mécanismes de l'ajout, de la suppression, du déplacement et du remplacement dans le but (p. 28) «d'aider à mieux connaître l'activité des écrivants».

3 Eduardo CALIL (Processus de création et ratures: analyse d'un processus d'écriture dans un texte rédigé par deux écolières, pp. 31-55) observe les ratures dans une optique lacanienne, les considérant comme le surgissement d'un tiers, l'Autre, dans l'écriture et comme un véritable «évènement d'énonciation» (p. 44). L'exemple de deux écolières qui doivent inventer une histoire en portugais permet de suivre la genèse d'une rature à partir d'un jeu homophonique qui s'explique en admettant la présence de l'inconscient freudien et des contraintes culturelles des écolières.

4 Irène fÉNOGLIO (Graphie manquée, lapsus écrit: un acte d'énonciation attesté, pp. 57-77) analyse les lapsus dans l'écriture d'Althusser et rédige une typologie, diversifiant le lapsus hapax du lapsus récurrent, ainsi que le lapsus de la faute de langue. Elle différencie également le lapsus écrit du lapsus oral, qui ont des modalités différentes.

5 MarC DERYCKE (Les graffitis bateliers: empreintes, suspensions...nomination, pp. 79-115) considère un corpus de graffitis bateliers repéré dans des ports français et en dresse une typologie (graffiti qui fait preuve, qui fait savoir). Tout en utilisant l'écriture au lieu 
du dessin, l'écriture des graffitis reste iconique, étant une sorte de sceau par lequel le graffiteur fait acte de reconnaissance sociale à travers la «scription» de la devise du bateau. Il s'agirait donc d'un alibi dont le graffiteur se servirait pour une «affirmation identitaire radicale» (p. 111). 